\title{
Discriminant analysis of farmers adoption of improved maize varieties in Wa Municipality, Upper West Region of Ghana
}

\author{
Abukari Alhassan ${ }^{1 *} \mathbb{D}$, Hussein Salifu ${ }^{1}$ and Atinuke O. Adebanji ${ }^{2}$
}

*Correspondence:
hassi1972@yahoo.com
' Department of Statistics,
Faculty of Mathematical
Sciences, University
for Development Studies,
P.O. Box 24, Navrongo, U/E
Region, Ghana
Full list of author information
is available at the end of the
article

*Correspondence: hassi1972@yahoo.com Faculty of Mathematical Sciences, University Region, Ghana article

\begin{abstract}
This study employed the quadratic classification function analysis to examine the influence of farmer's socio-demographic and varietal characteristics of maize on adoption of improved maize varieties (IMVs) in the Wa Municipality of the Upper West region of Ghana. The results showed that, farm labour, information availability about the variety, weed resistance, low yielding variety, early maturity and water stress resistance are the major discriminating variables in classifying farmers in the Municipality. The study however revealed that maize experience, low yield, information availability and cost of variety were the most influential discriminating variables between adopters and nonadopters of IMVs. The study recommended the need to improve on the level of farmers' education, ensure steady access to extension services and improvement in varietal characteristics identified in the study.
\end{abstract}

Keywords: Varietal attributes, Adoption, Discriminant analysis, Quadratic classification

\section{Background}

Maize is an adaptable crop, growing across a broad range of agro ecological zones. In Ghana, maize is a major source of carbohydrates and it is cultivated mostly in the southern regions, upper west, upper east and northern region of Ghana.

Maize also determines a household food security such that a low-income household is considered food insecured if it has no maize stock, regardless of other foods the household has at its disposal (Tweneboah 2000).

Ghana's maize export levels have increased over the years from 2000 to 5000 metric tons from 2012 to 2016. Current yield of maize in Ghana stands at 1 metric ton per hectare (www.indexmundi.com/agriculture/ghana). Worldwide production of maize is 785 million tons, with Africa producing $6.5 \%$ with the largest African producer being Nigeria with nearly 8 million tons, followed by South Africa. Africa imports about $28 \%$ of the required maize from countries outside the continent (IITA 2016).

The current levels of maize yield suggest that Ghana is still not self-sufficient in maize production. Some experts have attributed it to low adoption of productivity-enhancing technologies, including improved varieties and management practices. 
However, output variability is a major source of production risk under subsistence agriculture, especially when production depends solely on rainfall. Output variability affects both marginal gains and total farm output that influence food security at the household level. Food security is the most important priority for most subsistence farmers. Farmers prefer improved maize seeds that are stable in yield at different level of moisture availability (Moshi et al. 1990). Farmers avoid improved maize seeds that are highly variable in terms of yield as they pose food insecurity to households. The plan for reduction of yield variability will therefore influence which variety to adopt or not to adopt. At the household level, adoption choices are then formulated based on socioeconomic circumstances faced by the farmer and the attributes of the technology (CIMMYT 1993).

Ragasa et al. (2013), reported that, adoption of improved maize varieties (IMVs) have not seemed to increase since the 1997 survey of adoption. Out of the total maize area, $61 \%$ was planted with modern varieties while only $15 \%$ was planted with certified seeds. The research systems in the country have been very active in developing and releasing new varieties. They further intimated that, a 1992 variety, Obatanpa, is still the predominant variety and has gained popularity over the years than the newer varieties. This rather very high weighted-average varietal age (23 years) in Ghana signals that either the research system produces many irrelevant varieties that are not solving farmers' binding constraints or the agricultural extension system is unable to disseminate and educate farmers about the net benefits of new varieties.

Considerable literature exists in reporting attempts to explain the adoption of new IMVs using discriminant analysis (DA). Lakshman and Robert (1978) used DA to classify adoptors and Non adoptors of new variety of high yielding maize. Accessibility of resources was found to be a significant contributor to the adoption of high yielding maize. Luke et al. (2010) also used DA to investigate some factors that characterize farmers based on some starting conditions. Bashir and Wegrary (2014) studied the determinants of small holder farmers hybrid maize adoption in the drought prone Central Rift Valley of Ethiopia. They employed the linear discriminant function in their study to identify the significant socio-economic characteristics that discriminates among adoption of hybrid maize.

Thomson et al. (2014) used the logit model to model adoption of improved maize seed varieties in Southern Zambia. They also employed similar variables such as farmers age, maize farming experience, farm labour etc. Some other authors including Xiaolei et al. (2012) and Lee et al. (2007) have all developed classification procedures for selecting varieties of maize and maize hybrids respectively.

Based on the background literature, the determination of factors that contributes to adoption of IMVs in a population is imperative for the implementation of policy control measures as well as to improve livelihoods through sustainable increased productivity of maize.

The current study seeks to apply DA to classifying farmer's adoption of IMVs in the Upper West Region of Ghana based on their socio-economic characteristics and varietal characteristics of maize. 


\section{Methods}

\section{Sampling procedure}

This study involved a cross-sectional survey with 300 systematic sampled households growing maize in the two selected communities of Biihii and Kpongu in the Wa Municipality of Ghana. Biihii and Kpongu were selected purposely because of the importance of maize in the farming systems and the availability of maize technology dissemination programs in the two areas. Data was by means of a structured questionnaire, developed and used for gathering relevant information from the farmers. The instrument was administered to the respondents through a face-to-face interview of a convenient sample sizes of 135 households from Kpongu and 165 households from Beehii, with the assistance of the Savanna Agricultural Research Institute agents who interacted directly with the farmers at the local level.

\section{Background information of the study area}

The Upper West Region (UWR) is typical Guinea savannah, with a high density of tree species. Broadly speaking, the low population densities have permitted a remarkable conservation of savannah vegetation, quite unlike much of the remainder of Northern Ghana. The UWR forms part of savannah accelerated development authority (SADA) zone. The climatic regime is semi-arid with annual rainfall ranging between 700 and $1200 \mathrm{~mm}$. The rain falls in a 7-month season from April to October (Ghana Statistical Service 2010).

The Wa Municipality is one of the nine administrative areas (District Assemblies) that make up the Upper West Region (UWR) of Ghana. The Municipality lies within latitudes $1^{\circ} 40^{\prime \prime} \mathrm{N}-2^{\circ} 45^{\prime \prime} \mathrm{N}$ and longitudes $9^{\circ} 32^{\prime \prime}-10^{\circ} 20^{\prime \prime} \mathrm{W}$ (Ghana Statistical Service 2010). Wa Municipality has a total population of 702,110 . Wa town alone has a population size of 107,214 constituting $15.3 \%$ of the region's population. The growth rate of the Municipality varies between $2.7 \%$ for rural and $4 \%$ for the urban. Majority of the households $(30.9 \%)$ in the municipality are engaged in agriculture, with almost $82.9 \%$ of these agricultural households involved in crop farming (Ghana Statistical Service 2010). Figure 1 shows the map of Ghana indicating the study area.

\section{Discriminant analysis}

Discriminant analysis is a multivariate statistical technique used to determine which variables discriminate between two or more naturally occurring groups. Through DA, one may classify farmers into two or more mutually exclusive and exhaustive groups on the basis of a set of independent variables.

Linear discriminant/classification model $\left(\Sigma_{i}=\Sigma_{j}=\Sigma\right)$

Supposes the two population's $\pi_{1}$ and $\pi_{2}$ has multivariate normal densities $X^{\prime}=\left[x_{1}, x_{2}, \ldots, x_{p}\right]$ with mean vectors and covariance matrices, $\mu_{1}, \Sigma_{1}$ and $\mu_{2}, \Sigma_{2}$ respectively given by

$$
f_{i}(x)=\frac{1}{(2 \pi)^{p / 2}|\Sigma|^{1 / 2}} \exp \left[-\frac{1}{2}\left(x-\mu_{i}\right)^{\prime} \Sigma^{-1}\left(x-\mu_{i}\right)\right] \quad \text { for } i=1,2 .
$$




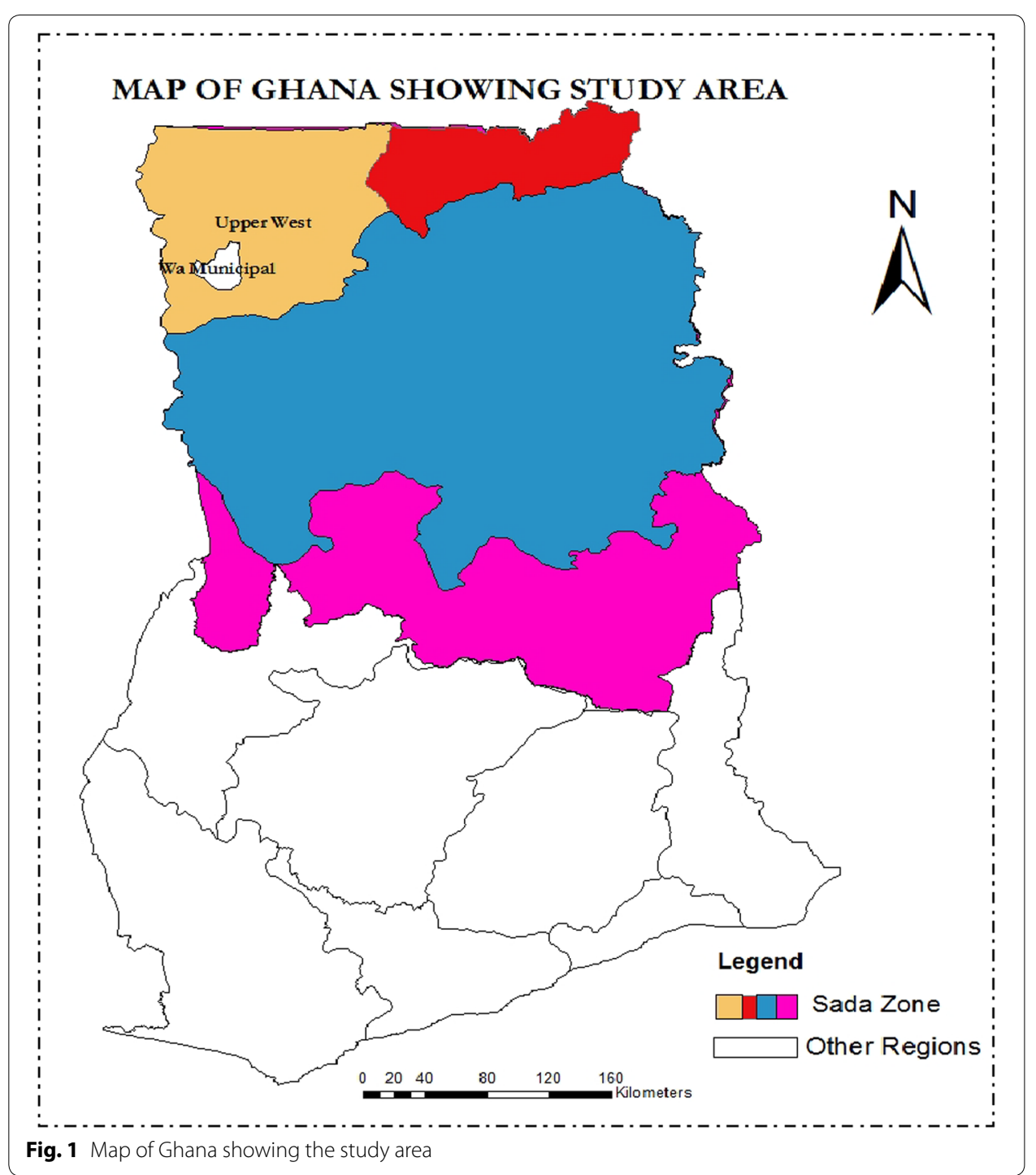

The allocation rule that minimizes the expected cost of misclassification (ECM) is given by:

Allocate $x_{0}$ to $\pi_{1}$ if

$$
\left(\mu_{1}-\mu_{2}\right)^{\prime} \Sigma^{-1} x_{0}-\frac{1}{2}\left(\mu_{1}-\mu_{2}\right)^{\prime} \Sigma^{-1}\left(\mu_{1}+\mu_{2}\right) \geq \ln \left[\left(\frac{c(1 / 2)}{c(2 / 1}\right)\left(\frac{p_{2}}{p_{1}}\right)\right]
$$

Allocate $x_{0}$ to $\pi_{2}$ otherwise (Johnson and Wichern 2007).

The population parameters in Eq. (2) can be replaced by its sample estimates; $\bar{x}_{1}, \bar{x}_{2}$ and $S_{\text {pooled }}$. Given a special case when there are equal prior probabilities and equal misclassification cost, then we assign $x_{0}$ to $\pi_{1}$ if:

$$
\left(\bar{x}_{1}-\bar{x}_{2}\right)^{\prime} S_{\text {pooled }}^{-1} x-\frac{1}{2}\left(\bar{x}_{1}-\bar{x}_{2}\right)^{\prime} S_{\text {pooled }}^{-1}\left(\bar{x}_{1}+\bar{x}_{2}\right)
$$


The quadratic classification model $\left(\Sigma_{i} \neq \Sigma_{j}\right)$

The decision boundary or the minimum expected cost of misclassification is based on the density ratio $f_{1}(x) / f_{2}(x)$. Substituting multivariate normal densities with different covariance matrices into Eq. (1) after taking natural logarithms and simplifying, the resulting classification regions are:

$$
\begin{aligned}
& R_{1}:-\frac{1}{2} x^{\prime}\left(\Sigma_{1}^{-1}-\Sigma_{2}^{-1}\right) x+\left(\mu_{1}^{\prime} \Sigma_{1}^{-1}-\mu_{2}^{\prime} \Sigma_{2}^{-1}\right) x-K \geq \ln \left[\left(\frac{c(1 / 2)}{c(2 / 1)}\right)\left(\frac{p_{2}}{p_{1}}\right)\right] \\
& R_{2}:-\frac{1}{2} x^{\prime}\left(\Sigma_{1}^{-1}-\Sigma_{2}^{-1}\right) x+\left(\mu_{1}^{\prime} \Sigma_{1}^{-1}-\mu_{2}^{\prime} \Sigma_{2}^{-1}\right) x-K \geq \ln \left[\left(\frac{c(1 / 2)}{c(2 / 1)}\right)\left(\frac{p_{2}}{p_{1}}\right)\right]
\end{aligned}
$$

The allocation rule that minimizes the expected cost of misclassification is given by replacing the population parameters with sample estimates, the minimum ECM then becomes:

Allocate $x_{0}$ to $\pi_{1}$ if

$$
-\frac{1}{2} x_{0}^{\prime}\left(S_{1}^{-1}-S_{2}^{-1}\right) x_{0}+\left(\bar{x}_{1}^{\prime} S_{1}^{-1}-\bar{x}_{2}^{\prime} S_{2}^{-1}\right) x_{0}-K \geq \ln \left[\left(\frac{c(1 \mid 2)}{c(2 \mid 1)}\right)\left(\frac{P_{2}}{P_{1}}\right)\right]
$$

Allocate $x_{0}$ to $\pi_{2}$ otherwise (Johnson and Wichern 2007).

Where

$$
K=\frac{1}{2} \ln \left(\frac{\left|\Sigma_{1}\right|}{\left|\Sigma_{2}\right|}\right)+\frac{1}{2}\left(\bar{x}_{1}^{\prime} S_{1}^{-1} \bar{x}_{1}-\bar{x}_{2}^{\prime} S_{2}^{-1} \bar{x}_{2}\right)
$$

$\left(\frac{c(1 \mid 2)}{c(2 \mid 1)}\right)$ is the expected cost ratio and $\left(\frac{P_{2}}{P_{1}}\right)$ is the prior probability ratio.

We assume that for each of the populations there are equal prior probabilities and equal misclassification cost, then the allocation rule reduces to

$$
-\frac{1}{2} x_{0}^{\prime}\left(S_{1}^{-1}-S_{2}^{-1}\right) x_{0}+\left(\bar{x}_{1}^{\prime} S_{1}^{-1}-\bar{x}_{2}^{\prime} S_{2}^{-1}\right) x_{0}-K \geq 1
$$

\section{Error rate estimation}

The holdout procedure sometimes referred to as jackknifing or cross-validation was used to evaluate the performance of the classification function. This method usually holds one observation at a time and classifies the hold out observation. This process is repeated until all observations are classified which produced almost unbiased estimates of the misclassification probabilities (Lachenbruch and Mickey 1968).

\section{Organization of data}

Adoption of IMVs was defined by two categories; adopters and non-adopters. The different categories of adoption were conceptually interpreted accordingly as follows: nonadopters means the farmer use local maize variety whiles adopters referred to farmers who used IMV.

The independent variables used in the study were some attributes of the improved varieties which were explored using a 5 -points Likert scaled with $1=$ No effect, $2=$ Little effect, $3=$ Not sure, $4=$ Moderate effect, $5=$ Extreme effect. These variables were as follows: storage/streak resistance, recycle grain (replanting), mature late, weed 
resistance, grain quality (grain colour/texture), low yield, water stress resistance, mature early, fertilizer requirement, information availability, diseases/pest resistances, soil fertility requirement and cost. In addition to these variables, farmers characteristics such as age of farmer, total farm labour and experience in maize farming were used in the analysis.

\section{Results and discussion}

The descriptive analyses of farmer's socio-demographic characteristics results in Table 1 revealed a mean age of 41 years with a standard deviation of 13.38 for farmers who are adopters of IMVs and a mean age of 39 years and a low standard deviation of 8.59 for non-adopters. With respect to mean farm labour, the result did not reveal much variation between the different categories of adoption. The results also showed higher years (11) of maize farming experience for adopters of IMVs as compared to non-adopters (9 years) of IMVs.

Seven (7) out of twenty-seven approved IMVs were found to be cultivated in the study areas. IMVs such as Obatanpa, Mamaba and Aburohemaa (34, 20.7 and $16.3 \%$ ) respectively were most popular. This may be as a result of the fact that, these varieties have been introduced quite a long time ago. The remaining varieties are quite new in the system hence its low patronage.

In order to investigate the determinants of adoption of IMVs, the Box M test of equality of population covariance matrices of the two groups of adoption under study was first tested. The log determinant of the groups was found as shown in Table 2. Under the null hypothesis of equal covariance matrices, the Box $M$ test was significant at $1 \%$ level, indicating a violation of the assumption of equal covariance matrices.

A quadratic classification function was then fitted to the data. Results of the quadratic classifier showed a significant performance at $1 \%$ significant level under the respective multivariate test statistics (Table 3). The test for differences in the mean vectors $\left(\mu_{1}\right.$ and $\mu_{2}$ ) is viewed as test for significance of the separation that is achieved. The QDF derived to classify farmers into their respective groups under unequal prior probability (Table 4) and equal misclassification cost has been determined and written as:

$$
\left(x-\bar{x}_{1}\right) S_{1}^{-1}\left(x-\bar{x}_{1}\right)-\left(x-\bar{x}_{2}\right) S_{2}^{-1}\left(x-\bar{x}_{2}\right) \geq 1.815
$$

Table 4 presents the result of classification and misclassification rates. $98.84 \%$ of the farmers were correctly classified as adopters of IMVs with a misclassification rate of 1.16 into the non-adopters group. However, none of the non-adopters of IMVs were misclassified and a $100 \%$ correct classification was achieved. Consequently, an overall error rate

Table 1 Descriptive statistics of some selected variables. Source: analysis from survey data in Beehi and Kpongu

\begin{tabular}{lcclll}
\hline Variables & \multicolumn{2}{l}{ Adopters } & & & \multicolumn{2}{l}{ Non-adopters } \\
\cline { 2 - 3 } & Mean & & & Mean & SD \\
\hline Farmer's age & 41.44 & 13.38 & & 38.75 & 8.59 \\
Farm labour & 5.41 & 3.34 & & 4.73 & 2.30 \\
Maize experience & 11.12 & 4.02 & & 9.13 & 3.19 \\
\hline
\end{tabular}


Table 2 Test for equality of population covariance matrices. Source: analysis from survey data in Beehi and Kpongu

\begin{tabular}{lccccc}
\hline Adoption & Rank & Log determinant & Chi square & df & P value \\
\hline Non-adopters & 9 & -159.91941 & 6033.3719 & 190 & $0.0001^{*}$ \\
Adopters & 19 & 1.9237 & & & \\
Pooled & 19 & 3.80536 & & & \\
\hline
\end{tabular}

* Significant at $1 \%$

Table 3 Test of model adequacy. Source: analysis from survey data in Beehi and Kpongu

\begin{tabular}{llllll}
\hline Test statistic & Value & F-value & DF1 & DF2 & P value \\
\hline Wilks'Lambda & 0.4942 & 14.98 & 19 & 278 & $0.0001^{*}$ \\
Pilla's Trace & 0.5058 & 14.98 & 19 & 278 & $0.0001^{*}$ \\
Hotelling Lawley Trace & 1.0235 & 14.98 & 19 & 278 & $0.0001^{*}$ \\
Roy's Greatest Rooa & 1.0235 & 14.98 & 19 & 278 & $0.0001^{*}$ \\
\hline
\end{tabular}

* Significant at $1 \%$

Table 4 Quadratic function classification results. Source: analysis from survey data in Beehi and Kpongu

\begin{tabular}{llll}
\hline & Classified & Adopters & Total \\
\cline { 2 - 4 } & Non-adopters & & 42 \\
\hline True/original & 42 & 0 & 100 \\
Non-adopters & 100 & 0 & 258 \\
Percent & 3 & 255 & 100 \\
Adopters & 1.16 & 98.84 & 300 \\
Percent & 45 & 255 & 100 \\
Total & 15 & 85 & 0.01 \\
Percent & 0 & 0.0116 & \\
Error rate & 0.14 & 0.86 & 42 \\
Priors & & & 100 \\
Cross-validation & 41 & 1 & 258 \\
Non-adopters & 97.62 & 2.38 & 100 \\
Percent & 3 & 255 & 300 \\
Adopters & 1.16 & 98.84 & 100 \\
Percent & 44 & 256 & 0.0133 \\
Total & 0.14 & 85.33 & \\
Percent & 0.238 & 0.0116 & \\
Error rate & & & \\
\hline
\end{tabular}

of 0.01 was achieved under the classification model. Further, the cross validation option provides a better assessment of classification accuracy. This classification is also done for each observation; however, the discriminant function used in each case was constructed by taking that observation out of the data set. Thus, every data point was reclassified as if it were a new unknown observation. This provided a more Conservative accuracy assessment. For this data, adopters of IMV's now showed an error rate of $1.16 \%$ while nonadopters of IMV's were $2.38 \%$. Overall, $13.3 \%$ of the observations were misclassified under the cross validation. The results also indicated that, in all approximately $99.0 \%$ 
(1-0.01) correct classification of farmers was achieved under classification with QDF as well as $98.67 \%(1-0.0133)$ correct classification rate under the cross validated results.

Another way of evaluating the performance of the discriminant function is to investigate the eigenvalue and the canonical correlation coefficient. The ability of a discriminant function to separate groups can be judged from the magnitude of the canonical correlation. If the total structure coefficient is equal to or greater than 0.30 it is considered useful (Johnson and Wichern 2007). The eigenvalue and the canonical correlation coefficient further affirmed that the model was correctly specified. The hypothesis that the canonical correlation in the current row and all that follows are zero was rejected at $5 \%$ significant level which further affirmed that QDF was correctly specified (See Table 5).

The performance of the model was further investigated using the receiver operating characteristic (ROC) curve (Fig. 2). The results showed a large Area Under the Curve (AUC) of $76.8 \%$ and significant $P$ value at $5 \%$ significant level which further affirmed that, the model was correctly specified. Also, the Tukey's test of additivity was significant $(F$-Value $=15.068$ and $P$ Value $=0.000)$ at the $5 \%$ level of significance indicating that, there is no multiplicative interaction among the items of the likert scale affirming the independence of the variables.

To identify the minimum number of variables that is important for discrimination and their level of significance in contributing to discrimination, the univariate test of class means was used (Table 6).The results indicated that, maize farming experience, variety availability, late maturing, weed resistance, low yield, fertilizer requirements, information availability and cost of variety was significant at $1 \%(P<0.01)$. While total farm labour, early maturity, and disease/pest resistance were significant at $5 \%(P<0.05)$. The results of the study contradicted earlier studies (Ebojei et al. 2012; Bashir and Wegrary 2014) which reported significant influence of farmer's age and farm size on adoption of improved seeds. However, the results confirmed earlier results of Thomson et al. (2014) and Cavane (2009) which indicated that, adoption of IMVs was influenced by expected yields, attitudes toward production trait of IMVs and knowledge (information availability).

The amount of variation explained by each discriminating variable is provided by the R-square which is adjusted for bias. The results show (See Table 6) that low yield, information availability and cost of variety explained large proportions of the variability $(9.16 \%, 7.17 \%$ and $8.35 \%)$ among the classes and hence indicates the level of contribution of these variables to group separation.

Table 5 Test of canonical correlation. Source: analysis from survey data in Beehi and Kpongu

\begin{tabular}{|c|c|c|c|c|c|c|}
\hline & Can. corr. & Adjt. can. corr. & Approx. SE & & corr. & Eigenvalue \\
\hline Function 1 & 0.711205 & 0.69074 & 0.028676 & & & 1.0235 \\
\hline Test & \multicolumn{2}{|c|}{ Likelihood ratio } & F-value & df & df & $P$ value \\
\hline Function 1 & \multicolumn{2}{|c|}{0.49418785} & 14.98 & 19 & 278 & $0.0001^{*}$ \\
\hline
\end{tabular}

Can. corr. canonical correlation

* Significant at $5 \%$ 


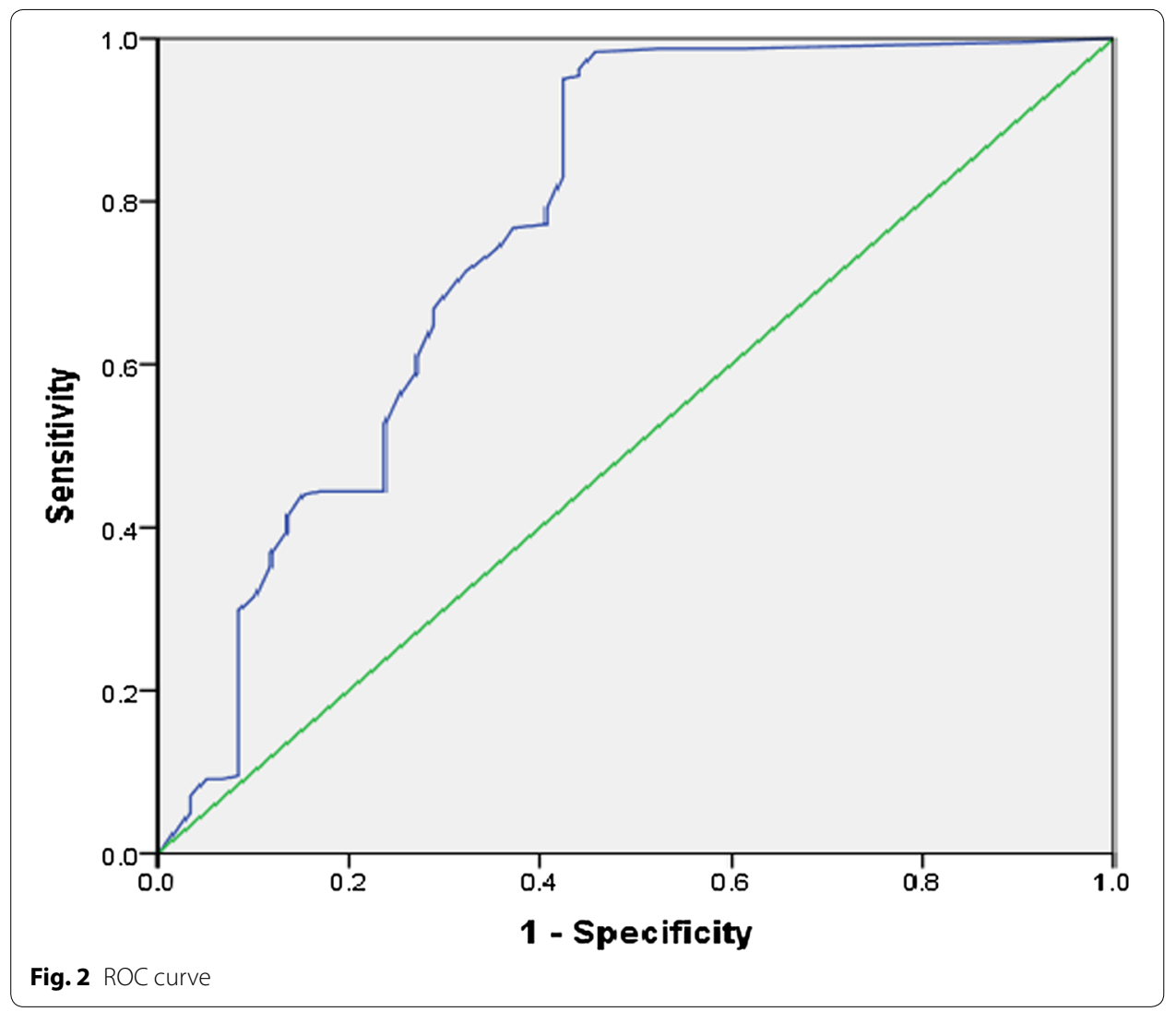

Table 6 Univariate test of class means. Source: analysis from survey data

\begin{tabular}{|c|c|c|c|c|c|}
\hline Variables & Total SD & R-square & Adjusted R-square & F-value & $P$ value \\
\hline Age of farmer's & 9.7611 & 0.0064 & 0.0064 & 1.89 & 0.1705 \\
\hline Total farm labour* & 2.5576 & 0.0147 & 0.0149 & 4.48 & 0.0367 \\
\hline Maize experience** & 3.4623 & 0.1663 & 0.0195 & 59.04 & 0.0001 \\
\hline High yield & 0.8418 & 0.0070 & 0.0070 & 2.06 & 0.1502 \\
\hline Availability** & 1.2566 & 0.0334 & 0.0346 & 10.23 & 0.0015 \\
\hline Storage/streek resistance & 1.0111 & 0.0001 & 0.0001 & 0.02 & 0.8791 \\
\hline Re-propagation & 0.9376 & 0.0000 & 0.0000 & 0.000 & 0.9630 \\
\hline Late maturity** & 1.2979 & 0.0224 & 0.0230 & 6.80 & 0.0096 \\
\hline Weed resistance ${ }^{* *}$ & 0.7878 & 0.0350 & 0.0362 & 10.72 & 0.0012 \\
\hline Grain quality & 1.1945 & 0.0053 & 0.0054 & 1.59 & 0.2089 \\
\hline Low yield** & 1.5180 & 0.0839 & 0.0916 & 27.12 & 0.0001 \\
\hline Water stress resistance & 1.2045 & 0.0008 & 0.0008 & 0.24 & 0.6277 \\
\hline Nutritional value & 1.2492 & 0.0000 & 0.0000 & 0.01 & 0.9183 \\
\hline Early maturity* & 1.1876 & 0.0203 & 0.0207 & 6.13 & 0.0138 \\
\hline Fertilizer requirement** & 1.3025 & 0.0464 & 0.0487 & 14.41 & 0.0002 \\
\hline Information availability** & 1.1023 & 0.0619 & 0.0717 & 21.24 & 0.0001 \\
\hline Disease/pest resistance* & 1.0839 & 0.0141 & 0.0143 & 4.24 & 0.0404 \\
\hline Soil fertility requirement & 0.9901 & 0.0011 & 0.0011 & 0.32 & 0.5735 \\
\hline Cost of variety ${ }^{* *}$ & 1.0399 & 0.0770 & 0.0835 & 24.71 & 0.0001 \\
\hline
\end{tabular}

** Significant at $1 \%$; ${ }^{*}$ significant at $5 \%$ level 
The structure matrix in Table 7 provides another way of studying the importance of the variables in the discriminant function. The ability of a discriminant function to separate groups can be judged from the magnitude of the canonical correlation. The results showed that, maize farming experience, low yield variety, fertilizer requirement, information availability and cost of variety are important discriminating variables. Thus a farmer with these attributes is more likely to adopt IMVs in the Wa municipal area.

It is also evident from the result (Table 7) that, maize farming experience, low yield, information availability and cost of variety has relative high coefficient value of 0.57 , $0.41,0.36$ and 0.39 respectively, and hence has a significant influence on discriminating between adopters and non-adopters of IMVs. This implies that, the more farmers are informed about IMVs the more likely they adopt the variety. Also, the results revealed that a more experienced farmer has a greater probability of adopting IMVs. On the other hand, the lower the yields of IMVs, the less likely farmers' adopt them. However, Hussein et al. (2015) reported negative influence of low yield and information availability on adoption of IMVs which contradicts the results of the current study. The results of this study supports the recommendations of Feder et al. (1985), Feder and Umali (1993) that, farmer perceptions of technology-specific characteristics significantly condition technology adoption decisions.

Table 8 presents standardized and unstandardized canonical discriminant coefficients of the QDF with class means of 2.46 and -0.41 respectively for non-adopters and adopters of IMVs. Future observations of farmers can be classified by evaluating the unstandardized canonical function. Farmers whose canonical coefficient is closer to the class means are classified as belonging to that class. The generalized squared distance function of the analysis is given as:

Table 7 Structure matrix. Source: analysis from survey data in Beehi and Kpongu

\begin{tabular}{lr}
\hline Variables & Function \\
\hline Age of farmer's & 0.111919 \\
Total farm labour & 0.170265 \\
Maize experience & 0.573367 \\
High yield & -0.117490 \\
Availability & 0.256953 \\
Storage/streak resistance & -0.012442 \\
Re-propagation & -0.003792 \\
Late maturity & 0.210645 \\
Weed resistance & -0.262888 \\
Grain quality & 0.102637 \\
low yield & 0.407332 \\
Water stress resistance & -0.039658 \\
Nutritional value & 0.008392 \\
Early maturity & -0.200340 \\
Fertilizer requirement & 0.302978 \\
Information availability & 0.363782 \\
Disease/pest resistance & 0.167080 \\
Soil fertility requirement & 0.040035 \\
Cost of variety & 0.390268
\end{tabular}


Table 8 Unstandardized and standardized canonical discriminant coefficient. Source: analysis from survey data in Beehi and Kpongu

\begin{tabular}{lcc}
\hline Variables & Unstandardized & Standardized \\
\hline Age of farmer's & -0.0019 & -0.0187 \\
Total farm labour & -0.0431 & -0.1102 \\
Maize experience & 0.2049 & 0.7093 \\
High yield & 0.0278 & 0.0234 \\
Availability & 0.1097 & 0.1378 \\
Storage/streak resistance & 0.1381 & 0.1396 \\
Re-propagation & -0.1134 & -0.1063 \\
Late maturity & 0.0662 & 0.0859 \\
Weed resistance & -0.6249 & -0.4924 \\
Grain quality & -0.1567 & -0.1872 \\
Low yield & 0.4759 & 0.7224 \\
Water stress resistance & 0.2399 & 0.2889 \\
Nutritional value & -0.0589 & -0.0736 \\
Early maturity & -0.1579 & -0.1875 \\
Fertilizer requirement & 0.1227 & 0.1599 \\
Information availability & 0.8568 & 0.9445 \\
Disease/pest resistance & -0.1497 & -0.1622 \\
Soil fertility requirement & -0.2946 & -0.2917 \\
Cost of variety & 0.3677 & 0.3824 \\
\hline
\end{tabular}

$$
D_{j}^{2}(x)=\left(x-\bar{x}_{(x) j}\right)^{\prime} S_{(x) j}^{-1}\left(x-\bar{x}_{(x) j}\right)+\ln \left|S_{(x) j}\right|
$$

The results of this study confirmed earlier research which indicated that adoption of improved maize technologies, was influenced by attitude toward varietal traits, knowledge to apply the technology, and the role of extension services in dissemination of improved technology (Kaliba et al. 2000; Abebaw and Belay 2001; Hintze et al. 2003; Gwary et al. 2012).

\section{Conclusions and recommendations}

In this study, the determinants of adoption of IMVs in the Wa Municipality of the Upper West Region of Ghana were investigated. The results show that farm labour, maize experience, availability of variety, information availability, low yield, early maturity, fertilizer requirement and cost of variety were the major discriminating variables in classifying farmers in the study areas. The study revealed that maize experience, low yield, information availability and cost of variety were the most influential discriminating variables between adopters and non-adopters of IMVs. It is therefore recommended that soil scientists and crop breeders should consider an improvement in the specific varietal characteristics identified as influencing adoption of IMVs. Priority can be given to development of maize varieties whose fertilizer requirement is low and which are early maturing and high yield. Also agricultural extension division of the Ministry of Food and Agriculture (MOFA) should consider organizing on-farm trials with the farmers in order to accelerate their adoption of the IMVs. The ministry of Agriculture through the public 
information department should intensify public educations through radio, community dabbers and any available platform to increase farmer's knowledge on new agricultural technologies.

\section{Authors' contributions}

AA carried out the data analysis including the application of Discriminant analysis. HS worked on the background as well as materials and methods. AOA reviewed and edited the work thoroughly. All authors read and approved the final manuscript.

\section{Author details}

1 Department of Statistics, Faculty of Mathematical Sciences, University for Development Studies, P.O. Box 24, Navrongo, U/E Region, Ghana. ${ }^{2}$ Department of Mathematics, Kwame Nkrumah University of Science and Technology, Kumasi, Ghana.

\section{Acknowledgements}

We are very grateful to Mr. Hashim Ibrahim and Mr. Solomon Antuona of the Savanna Agricultural Research Institute (SARI) Wa division for facilitating the administering of the questionnaires in the study area.

\section{Competing interests}

The authors declare that they have no competing interests.

Received: 18 May 2016 Accepted: 1 September 2016

Published online: 08 September 2016

\section{References}

Abebaw D, Belay K (2001) Factors influencing adoption of high yielding maize varieties in Southwestern Ethiopia: an application of logit. Q J Int Agric 40(2):149-167

Bashir B, Wegrary D (2014) Determinants of smallholder farmers hybrid maize adoption in the drought prone Central Rift Valley of Ethiopia. Afr J Agric Res 9(17):1334-1343

Cavane E (2009) Farmers' attitudes and adoption of improved maize varieties and chemical fertilizers in Mozambique. Afr Crop Sci Conf Proc 9:163-167

CIMMYT (1993) The adoption of agricultural technologies: a guide for survey design. International Wheat and Improvement Center, Londres

Ebojei CO, Ayinde TB, Akogwu GO (2012) Socio-economic factors influencing the adoption of hybrid maize in Giwa Local Government Area of Kaduna State, Nigeria. J Agric Sci 7:1

Feder G, Umali D (1993) The adoption of agricultural innovations: a review. Technol Forecast Soc Change 43:215-239

Feder G, Just RE, Zilberman D (1985) Adoption of agricultural innovations in developing countries: a survey. Econ Dev Cult Change 33:255-297

Ghana Statistical Service (2010) Population and housing census. Ghana Statistical Service, Accra

Gwary MM, Gwary TM, Mustapha SB (2012) Discriminant analysis of the influence of farmers' socio-economic characteristics on their participation in research and extension activities in Borno State, Nigeria. Int Res J Soc Sci 4:1-6

Hintze LH, Renkow M, Sain G (2003) Variety characteristics and maize adoption in Honduras. J Agric Econ 29:307-317

Hussein S, Abukari A, Katara S (2015) Determinants of farmers adoption of improved maize varieties in the Wa Municipality. Am Int J Contemp Res 5(4):27-35

IndexMundi (2016) Ghana corn yield by year. http://www.indexmundi.com/agriculture/?country=gh\&commodity=corn \&graph=yield. Accessed 26 Aug 2016

International Institute of Tropical Agriculture (IITA) (2016) Experts convene to deliberate how to make food and feed safe from Aflatoxins in Africa. July 13, 2016. http://www.iita.org/maize. Accessed 26 Aug 2016

Johnson RA, Wichern DW (2007) Applied multivariate statistical analysis, 6th edn. Prentice Hall, Upper Saddle River

Kaliba RMA, Verkuijl H, Mwangi W (2000) Factors affecting adoption of improved maize seeds and use of inorganic fertiliser for maize production in the intermediate and lowland zones of Tanzania. J Agric Appl Econ 32(1):35-47

Lachenbruch PA, Mickey MA (1968) Estimation of error rates in discriminant analysis. Technometrics 10(15):1-11

Lakshman SY, Robert CM (1978) Non-adoption of innovations: evidence from discriminant analysis. Econ Geogr 54(2):145-156

Lee KM, Herrman TJ, Bean SR, Jackson DS, Lingenfelser J (2007) Classification of dry-milled maize grit yield groups using quadratic discriminant analysis and decision tree algorithm. Cereal Chem 84(2):152-161

Luke OO, Tahirou A, Alpha K, Joachim B, Adewale A (2010) Using a linear discriminant analysis approach of baseline conditions to develop household categories in the Sudan Savanna. J Food Agric Environ 8(2):805-812

Moshi A, Mduruma JO, Lyimo NG, Marandu WF, Akonaay HB (1990) Maize breeding for target environments in Tanzania. In: Dares-Salaam (ed) Maize research in Tanzania national maize research workshop. TARO, Tanzania

Ragasa C, Dankyi A, Acheampon P, Wiredu AN, Chapo-to A, Asamoah M, Tripp R (2013) Patterns of adoption of improved maize technologies in Ghana. GSSP working paper no. 35. International Food Policy Research Institute, Washington

Thomson K, Gelson T, Elias K (2014) Adoption of improved maize seed varieties in Southern Zambia. Asian J Agric Sci $6(1): 33-39$

Tweneboah CK (2000) Modern agriculture in the tropics with special reference to Ghana. Co-Wood Publishers, Accra

Xiaolei Z, Fei L, Yong H, Xiaoli L (2012) Application of hyperspectral imaging and chemometric calibrations for variety discrimination of maize seeds. Sensors 12:17234-17246 